\title{
Exploring sex differences in drug use, health and service use characteristics among young urban crack users in Brazil
}

\author{
Neilane Bertoni ${ }^{3}$, Chantal Burnett ${ }^{4}$, Marcelo Santos Cruz ${ }^{1}$, Tarcisio Andrade ${ }^{2}$, Francisco I Bastos ${ }^{3}$, Erotildes Leal ${ }^{1}$
} and Benedikt Fischer ${ }^{4,5^{*}}$

\begin{abstract}
Introduction: Studies have shown important gender differences among drug (including crack) users related to: drug use patterns; health risks and consequences; criminal involvement; and service needs/use. Crack use is prevalent in Brazil; however, few comparative data by sex exist. We examined and compared by sex key drug use, health, socio-economic indicators and service use in a bi-city sample of young (18-24 years), regular and marginalized crack users in Brazil.

Methods: Study participants (total $n=159 ; n=124$ males and $n=35$ females) were recruited by community-based methods from impoverished neighborhoods in Rio de Janeiro and Salvador. Assessments occurred by an anonymous interviewer-administered questionnaire and serum collection for blood-borne virus testing between November 2010 and June 2011. Descriptive statistics and differences for key variables by sex were computed; in addition, a 'chi-squared automatic interaction detector' ('CHAID') analysis explored potential primary factors differentiating male and female participants.

Results: Most participants were non-white, and had low education and multiple income sources. More women had unstable housing and income from sex work and/or panhandling/begging, whereas more men were employed. Both groups indicated multi-year histories of and frequent daily crack use, but virtually no drug injection histories. Men reported more co-use of other drugs. More women were: involved in sex-for-drug exchanges; Blood-Borne Virus (BBV) tested and $\mathrm{HIV}+$. Both groups reported similar physical and mental health patterns; however women more commonly utilized social or health services. The CHAID analysis identified sex work; paid work; begging/panhandling; as well as physical and mental health status (all at $\mathrm{p}<0.05$ ) as primary differentiating factors by sex.

Conclusions: Crack users in our study showed notable differences by sex, including socio-economic indicators, drug co-use patterns, sex risks/work, BBV testing and status, and service utilization. Results emphasize the need for targeted special interventions and services for males and female crack users in Brazil.
\end{abstract}

Keywords: Crack use, Gender, Health, Interventions, Brazil, Marginalized populations

\footnotetext{
* Correspondence: bfischer@sfu.ca

${ }^{4}$ Centre for Applied Research in Mental Health and Addiction, Faculty of

Health Sciences, Simon Fraser University, Vancouver, Canada

${ }^{5}$ Social \& Epidemiological Research, Centre for Addiction and Mental Health,

Toronto, Canada

Full list of author information is available at the end of the article
} 


\section{Introduction}

Research has documented a number of important differences between male and female users of - both licit and illicit - substances. While for many substance categories, women typically feature lower prevalence levels of use and problems than men, there appear to be some important differences in pathways to problems [1,2]. For example, several key studies document that women more quickly progress from use onset to problematic use ('telescoping'), including manifested substance use disorders or need for treatment [3-5].

Women develop more severe medical or health problem consequences from substance use than men [6,7]. While women are typically less involved in substance use-related overt deviance (e.g., violence or crime), data from several studies suggest higher levels of co-morbid psychological or psychiatric problems among women users; specifically, large $(30 \%-50 \%)$ proportions of women substance users report a history of (sexual or other) trauma and/or related Post-traumatic stress disorder (PTSD) $[1,2,8]$. In addition, larger proportions of women indicate co-morbid mood (e.g., depression) and/or anxiety disorders; however, the evidence is inconsistent about the directionality or sequence of these co-morbidities [1,9-11].

Data suggests that biology-related sex differences may influence differential drug use or problem patterns; for example, women may be more vulnerable to the reinforcing effects of psycho-stimulants during key developmental phases leading to dependence [12]. Women appear to enter substance use treatment less frequently than men, but commonly enter treatment driven by different factors (e.g., related to child care concerns), implying differential treatment needs. While a lack of targeted services for women drug users has been described for several countries, gender does not seem to majorly affect treatment retention, completion or outcomes [5,13-17].

Crack users are a specific population of substance users for which distinct gender differences have been reported. Many female users report initiation into crack use by an intimate partner, and use patterns and risks are commonly shaped by the power dynamics within an intimate relationship with a drug-using partner $[18,19]$. Women crack users commonly report more frequent or problematic (e.g., 'bingeing') crack use [20-22] as well as substantially more pronounced sexual risk behaviors related to crack use; for example, they are more commonly involved in sex work, and/or risky sexual behaviors (e.g., unprotected sex) in exchange for money or crack [23-28]. These gendered risk behavior patterns have translated into a higher prevalence of sex-risk related health problems including higher prevalence of Blood-Borne Viruses (BBVs) or Sexually Transmitted Diseases (STDs) - among female crack user populations (e.g., Human Immunodeficiency
Virus (HIV) and/or Hepatitis C Virus (HCV)) $[22,29,30]$. Overall, female crack users commonly feature lower selfreported health status than their male counterparts [25,31]; however there do not seem to be major gender-differences in treatment seeking, retention or outcomes [13,32].

Crack use has become a prevalent street drug use phenomenon in Brazil in recent years, associated with considerable health and social harms, as well as intensive discussions about appropriate interventions [33-36]. While previous estimates have been higher, a recent study estimated a population of some 370,000 crack users in the 27 Brazilian capital cities [37]. Most users have been shown to be young, socio-economically marginalized (e.g., poor/ unemployed) and under-housed; further, most surveys typically only find a minority of crack users to be women [37-39].

In studies of different crack user populations attending in-patient or community-based treatment programs, only small minorities were females [40-42], offering only limited data on the distinct characteristics of female users, or potential differences between male and female users in Brazil. In a sample of pregnant crack users in in-patient detoxification treatment, $25 \%$ reported frequent daily crack use ( $>20$ rocks per day); most had poly-substance use (e.g., tobacco, alcohol, cannabis). Close to half reported sex work, i.e. exchange of sex for money or drugs $(45 \%)$ and crime involvement (e.g., robbery; $41 \%$ ), and $15 \%$ were HIV-positive and $6 \%$ were HCV-positive [43]. Some other studies reported high prevalence of sex work and/or unsafe sex among female crack users in Brazil. In a sample of crack users in inpatient treatment, women were more likely to report sexwork involvement (and related HIV transmission risks) than men [44]. Community-based samples of crack users in Salvador and São Paulo reported high levels of unsafe sex and sex-for-money/drug-exchange activities as strategies to obtain crack among female participants, some of which also occurred in the distinct contexts of women obtaining crack for their intimate partners [35,45-50]. The pronounced sexual risk behavior patterns among female crack users in Brazil are directly linked to highly elevated transmission risk and prevalence of BBVs as well as exposure to violence and victimization $[43,49,51]$. Recent data suggest an increasing trend in the proportion of women crack users presenting in local health care facilities, which may either point to increasing use prevalence or increasing service utilization [52]. While substantive investments for substance use related health and treatment services (e.g., CAPS-AD, Therapeutic Community funding) have been made in Brazil, the need for special and targeted services for women has been emphasized given their distinct problem and needs profiles $[35,43,44]$.

This paper examined gender-specific drug use, health, socio-economic and service use characteristics - and 
explored potential differences between males and females - among a community-recruited bi-site sample of young, regular crack users in Brazil.

\section{Methods}

This study utilized data from a cross-sectional multi-site study of regular street-involved crack users recruited from impoverished neighborhoods in Rio de Janeiro (e.g., Jacarezinho) and Salvador (e.g., Pelourinho, Calabar, Ribeira, Fazenda Coutos and Valéria) with known extensive crack user populations (see [39] for details). Recruitment was facilitated by community-based contact persons (e.g., community workers) with direct access to the target population who disseminated basic study information to potential participants; study candidates were then assessed for eligibility by study field staff based on a brief screening protocol.

Eligibility criteria included: 1) crack use on three days + per week in the last three months; 2) 18-24 years of age; and 3) consent to participate in the full study protocol. Individuals experiencing acute intoxication or mental health problems, or displaying problematic behavior impeding assessment were not included. If eligible, and following written consent, study participants were assessed in a private study space at one of the community-based local study offices in either site.

A total of 175 (95 in Rio and 80 in Salvador) individuals were screened for eligibility; 15 were excluded for age or drug use criteria; a total of $n=160$ study assessments $(81 / 79)$ were completed between November 2010 and June 2011. Assessments consisted of an interviewer-administered questionnaire with 31 mainly quantitative items on socio-demographic, health and drug use characteristics, and service use/needs; in addition, blood specimens were collected by venipuncture and subsequently tested for $\mathrm{HBAg}$, anti-HBc total, anti-HBs, total anti-HAV, anti-HCV, and anti-HIV using commercial enzyme immunoassays. All data and samples were sent to the Oswaldo Cruz Foundation (FIOCRUZ, RJ) for processing and analyses. Questionnaire data were scanned using Teleform ${ }^{\odot}$ procedures and manually quality-checked; statistical analysis were conducted using STATA v.9.

One subject was excluded from analysis due to unspecified sex, resulting in a basic analysis sample of $n=159$ ( $\mathrm{n}=124$ males and $\mathrm{n}=35$ females). Descriptive analysis e.g., proportions for categorical variables, mean/median values for continuous variables - for key variables of interest were computed and reported by sex. Statistical tests for differences between males and females (e.g., chi-squares for categorical variables, $\mathrm{t}$-tests for continuous variables with $\mathrm{p}$-value set at $\mathrm{p}<0.05)$ were conducted.

Subsequently, a CHAID ('Chi-squared automatic interaction detector') algorithm was used to examine potential factors independently differentiating between males and female study participants [53,54]. The CHAID analysis essentially constitutes a non-binary tree classification method focusing on independent predictor factors or 'nodes' of classification into a dependent characteristic (here: sex). This occurs by a stepwise procedure in which the most significant variable (the largest $\chi^{2}$ ) is used to partition the sample into mutually exclusive subgroups. The cases in the emerging subgroups are further partitioned by the next most significant variable related to the dependent variable of interest, until there are no more significant variables. All variables were considered statistically significant at $\mathrm{p}$-value $<0.05$. Cases with missing data for any of the variables examined $(n=6)$ were excluded from the CHAID analysis, resulting in an analysis sample of $n=153$. The software used for this analysis was SPSS v.19.

Considering the dichotomous dependent variable of sex (male vs. female), the independent variables selected were: Education (some elementary school or less vs. completed elementary school or higher); housing status (stable vs. unstable or homeless); formal or informal work for income (yes vs. no); illegal activities for income (yes vs. no); begging/panhandling for income (yes vs. no); sex work for income and/or source to obtain drugs (yes vs. no); alcohol use (yes vs. no); marijuana use (yes vs. no); cocaine use (yes vs. no); daily crack use (yes vs. no); overdose (yes vs. no); sharing crack paraphernalia (yes vs. no); unprotected sex (yes vs. no); HIV (serology) status (positive vs. negative); Hepatitis A status (reagent vs. non-reagent); Hepatitis B status (reagent vs. nonreagent); Hepatitis $C$ status (reagent vs. non-reagent); physical health status ('good' or better vs. 'fair' or worse); mental health status ('good' or better vs. 'fair' or worse); arrest (yes vs. no). Except for 'education' and 'arrest' (in past year), the reference period for all variables was in past 30 days' prior to the assessment.

The study protocol was approved by the Ethical Review Committee, Institute of Psychiatry, Federal University of Rio de Janeiro as well as the Brazilian National Ethics Committee (CONEP 519/2010).

\section{Results}

Mean age of the samples was 21 years (range 18-24; Standard Deviation [SD] + 2.2) for females, and 22 years (18-24; SD 2.1) for males. Most respondents were of non-white (i.e., black or mixed) race, single and had some elementary school or less education. Significantly more females than males were characterized by unstable housing or homelessness. Close to half of men, and one third of females had been arrested in the past year. Both men and women had a variety of income sources; while the most common income sources for men were employment or some sort of paid work, more women relied on sex work and/or begging/panhandling for income 
generation, with illegal activities and support or transfer payments less common for both sexes (Table 1).

Participants had an average history of 4 (SD: 3.0; males) and 5 (SD: 3.4; females) years of crack use, and used an average of 10 (SD: 11) and 8 (SD: 6) rocks of crack per day, respectively. The majority of both males and females were current tobacco users; while men also commonly reported current use of marijuana, alcohol or cocaine, women reported lower use prevalence of these drugs. The use of other drugs was either marginally small or non-existent (Table 2).

Very few participants reported a lifetime injection drug history, or a recent overdose experience. While majorities of both males and females reported unsafe sex activities, more females had recent sex-for-drug/money exchanges. More women had been tested for HIV and $\mathrm{HCV}$; almost five times as many women as men were determined to be HIV+. Close to half of both men and women rated their physical health as 'good' or better. Similar rates reported physical health problems; most of those with problems did not receive medical attention yet would have liked to do so. Similar patterns emerged for mental health, except that more men than women rated their mental health as 'good' or better. Twice as many women recently utilized any kind of social, health or treatment service; social services were most commonly used, followed by health and treatment services, respectively. Substantive majorities among both sub-groups indicated that they would use specific help services for drug users if available to them (Table 3).

In the results of the CHAID analysis (Figure 1), the most important variable differentiating male and female participants was sex work for income and/or to get drugs $(\mathrm{p}<0.000)$. Among the individuals involved in sex work, male respondents more frequently than females reported involvement in formal/informal work $(\mathrm{p}=0.017)$. Among participants without sex work involvement, engaging in begging/panhandling for income $(p=0.003)$ emerged as the differentiating factor by sex. Among respondents with begging for income, physical health status ( $\mathrm{p}=0.011$ ) was the main differentiating factor by sex; among respondents not involved in begging, formal or informal work ( $\mathrm{p}=0.017)$, again, was the principal differentiating factor; finally, among respondents who indicated neither begging nor formal/informal work as income sources, mental health status $(\mathrm{p}=$

Table 1 Socio-demographic characteristics, employment status, income generation and arrest history of sample, by sex

\begin{tabular}{|c|c|c|c|c|}
\hline & $\begin{array}{l}\text { Men }(n=124) \\
\text { mean (SD) }\end{array}$ & $\begin{array}{l}\text { Women }(n=35) \\
\text { mean }(S D)\end{array}$ & Test statistic $t$ & P-value \\
\hline \multirow[t]{2}{*}{ Age } & $20.7(2.1)$ & $21.6(2.2)$ & $2.174^{*}$ & \\
\hline & $\mathbf{N}(\%)$ & $\mathbf{N}(\%)$ & $x^{2}$ & \\
\hline Race & & & 0.3905 & 0.532 \\
\hline White & $11(9.0)$ & $2(5.7)$ & & \\
\hline Non-White/Other & $111(91.0)$ & $33(94.3)$ & & \\
\hline Marital Status & & & 0.6712 & 0.413 \\
\hline Single/separ/div/widow & $100(80.6)$ & $26(74.3)$ & & \\
\hline Married or cohabitating & $24(19.4)$ & $9(25.7)$ & & \\
\hline Education $^{a}$ & & & 0.1736 & 0.677 \\
\hline Some elementary school or less & $102(82.3)$ & $29(85.3)$ & & \\
\hline Completed elementary school or higher & $22(17.7)$ & $5(14.7)$ & & \\
\hline Housing status ${ }^{\mathrm{a}}[30]$ & & & $13.2492^{*}$ & 0.000 \\
\hline Stable housing & $71(57.7)$ & $8(22.9)$ & & \\
\hline Unstable housing or homeless & $52(42.3)$ & $27(77.1)$ & & \\
\hline \multicolumn{5}{|l|}{ Income sources [30] } \\
\hline Formal or informal transfers (e.g., social assistance, money from family/friends) & $35(28.2)$ & $10(28.6)$ & 0.0016 & 0.968 \\
\hline Paid employment/work & $82(66.1)$ & $6(17.1)$ & $26.503^{* * *}$ & 0.000 \\
\hline Illegal activities (including drug-related work) & $25(20.2)$ & $4(11.4)$ & 1.396 & 0.237 \\
\hline Sex work & $3(2.4)$ & $16(45.7)$ & $48.627^{* * *}$ & 0.000 \\
\hline Begging/panhandling & $19(15.3)$ & $14(40.0)$ & $10.107^{* * *}$ & 0.001 \\
\hline \multicolumn{5}{|l|}{ Arrest history } \\
\hline Detained by police (past year) & $56(45.2)$ & $11(31.4)$ & 2.111 & 0.146 \\
\hline
\end{tabular}


Table 2 Crack and other drug use characteristics of sample, by sex

\begin{tabular}{|c|c|c|c|c|}
\hline & Men $(n=124)$ M (SD) & Women $(n=35) M(S D)$ & Test statistic $\mathbf{t}$ & P-value \\
\hline Number of years of crack use & $4.0(3.0)$ & $4.9(3.4)$ & 1.547 & \\
\hline \multirow[t]{2}{*}{ Number of crack rocks used per typical day } & $10.1(10.5)$ & $8.3(5.9)$ & 0.925 & \\
\hline & $\mathbf{N}(\%)$ & $\mathbf{N}(\%)$ & $x^{2}$ & \\
\hline Daily crack use [30] & $66(53.2)$ & $24(68.6)$ & 2.617 & 0.106 \\
\hline \multicolumn{5}{|l|}{ Main modes of crack use } \\
\hline Smoking mixed crack and tobacco & $7(5.7)$ & $2(5.7)$ & 0.0002 & 0.988 \\
\hline Smoking mixed crack and marijuana & $29(23.4)$ & $1(2.9)$ & $7.5154^{*}$ & 0.006 \\
\hline Smoking crack using a can & $8(6.5)$ & $2(5.7)$ & 0.0252 & 0.874 \\
\hline Smoking crack using a plastic cup & $50(40.3)$ & $22(62.9)$ & $5.5941^{*}$ & 0.018 \\
\hline Smoking crack using a pipe & $28(22.6)$ & $8(22.9)$ & 0.00123 & 0.972 \\
\hline Shared crack smoking implements [30] ${ }^{a}$ & $72(62.1)$ & $21(60.0)$ & 0.0487 & 0.825 \\
\hline \multicolumn{5}{|l|}{ Other drug use $[30]^{a}$} \\
\hline Alcohol & $68(55.7)$ & $9(25.7)$ & $9.8100^{* *}$ & 0.002 \\
\hline Tobacco & $97(78.2)$ & 31 (88.6) & 1.8614 & 0.172 \\
\hline Marijuana & $88(71.5)$ & $18(51.4)$ & $4.9936^{*}$ & 0.025 \\
\hline Amphetamines or LSD & $0(0.0)$ & $0(0.0)$ & - & - \\
\hline Cocaine & $55(45.8)$ & $4(11.4)$ & $13.6049 * * *$ & 0.000 \\
\hline Benzodiazepines & $3(2.4)$ & $0(0.0)$ & 0.8702 & 0.351 \\
\hline Opioids & $0(0.0)$ & $0(0.0)$ & - & - \\
\hline Inhalants/Solvents & $4(3.4)$ & $2(5.9)$ & 0.4325 & 0.511 \\
\hline
\end{tabular}

${ }^{*} \mathrm{p}<0.05,{ }^{* *} \mathrm{p}<0.01,{ }^{* * *} \mathrm{p}<0.001$.

${ }^{\text {a }}$ subjects with missing data not included. [30]: in the last 30 days.

0.012) emerged as the main differentiating factor between males and females.

\section{Discussion}

Our study's results revealed several key areas of differences between males and females in our bi-city sample of young crack users in Brazil, with implications for interventions and further research.

First, our findings - both from univariate and the CHAID analyses - indicated key differences in income generation behaviors between male and female participants. While most men reported some form of paid work, the largest proportion of women reported involvement in sex work and/or begging/panhandling for income generation. These results extend findings from several other studies with crack users elsewhere, suggesting pronounced patterns of 'gendering' related to income sourcing in this population. That is, while men are more commonly involved in legal or illegal 'work' or crime activities, women commonly rely on commercial sex or other forms (e.g., begging/panhandling) of income generation $[24,26,55,56]$. These patterns bring several implications. First - while our data did not specify what 'work' concretely meant - the predominant exclusion of women from more ordinary 'work' activities and primary reliance on sex work or begging may entail an even more pronounced socio-economic 'marginalization' of female users than is already generally the case for this population $[55,57,58]$. These marginalization dynamics may further negatively influence the risks and consequences of drug use, as well as engagement with or access to key basic (e.g., social or health) services and interventions, and hence amplify the overall negative circumstances of women crack users. Second, our results confirm findings of other studies from different jurisdictions (including some from Brazil) documenting the common and intensive involvement of female crack users in sex work $[43,51,59,60]$. Sex work involvement among female crack users is well documented to be strongly associated with key health risks - e.g., unprotected sex, unsafe sex practices, multiple sex partners, acute BBV transmission, often occurring in the context of crack use 'binges' - as well as exposure to violence and related victimization [20,21,23,25,27,60]. Commonly, commercial sex work among female crack users occurs within the imbalanced power dynamics of intimate relations with male crack user partners, where women are charged with procuring funds to acquire drugs for themselves and their partner $[18,49]$. Given the high prevalence of sex work for income among female users and its key consequences (see also below) in our sample, implementing interventions to reduce sex work involvement and/or or 
Table 3 Health risk, status and service utilization characteristics of sample, by sex

\begin{tabular}{|c|c|c|c|c|}
\hline & Men $(n=124) N(\%)$ & Women $(n=35) N(\%)$ & Test statistic $\mathrm{x}^{2}$ & p-value \\
\hline \multicolumn{5}{|l|}{ Sexual Risks } \\
\hline Had sex without a condom [30] & $75(60.5)$ & $22(62.9)$ & 0.0646 & 0.799 \\
\hline Had sex in exchange for drugs in [30] & $5(4.0)$ & $10(28.6)$ & $19.2377^{* * *}$ & 0.000 \\
\hline \multicolumn{5}{|l|}{ Health status } \\
\hline Drug overdose [30] & $8(6.5)$ & $1(2.9)$ & 0.6257 & 0.429 \\
\hline Injection drug use (lifetime) & $2(1.6)$ & $0(0.0)$ & 0.5717 & 0.450 \\
\hline Oral sores/injuries [30] & $18(14.8)$ & $5(14.3)$ & 0.0048 & 0.945 \\
\hline Ever tested for HIV & $27(22.3)$ & $26(76.5)$ & $34.5957^{* * *}$ & 0.000 \\
\hline HIV + (serology) & $5(4.1)$ & $6(18.9)$ & $7.8139 * *$ & 0.005 \\
\hline Ever tested for Hep C & $9(7.6)$ & $18(60.0)$ & $43.9874^{* * *}$ & 0.000 \\
\hline Hep C + (HCVAB serology) & $0(-)$ & $1(3.0)$ & 3.7210 & 0.054 \\
\hline Hep B serology & $17(13.9)$ & $9(28.1)$ & 3.6379 & 0.056 \\
\hline Hep A serology & $99(81.2)$ & 29 (90.6) & 1.6227 & 0.203 \\
\hline Physical health problems [30] & $52(42.6)$ & $16(45.7)$ & 1.0754 & 0.584 \\
\hline Received medical attention ${ }^{\mathrm{b}}$ & $7(12.7)$ & $5(31.3)$ & 3.0277 & 0.082 \\
\hline Would like to receive medical attention ${ }^{\mathrm{b}}$ & $40(78.4)$ & $12(75.0)$ & 3.1357 & 0.077 \\
\hline Self-rated physical health ${ }^{a}$ & & & 0.5902 & 0.422 \\
\hline 'Good' or better & $49(41.5)$ & $12(34.3)$ & & \\
\hline Mental health problems [30] & $58(46.8)$ & $15(42.9)$ & 0.8137 & 0.666 \\
\hline Received medical attention ${ }^{\mathrm{b}}$ & $1(1.75)$ & $0(-)$ & 0.2491 & 0.618 \\
\hline Would like to receive medical attention ${ }^{\mathrm{b}}$ & $38(66.7)$ & $10(71.4)$ & 0.1164 & 0.733 \\
\hline Self-rated mental health & & & $4.4885^{*}$ & 0.034 \\
\hline 'Good' or better & $63(52.9)$ & $11(32.4)$ & & \\
\hline \multicolumn{5}{|l|}{ Service utilization } \\
\hline Accessed social, health or drug treatment services [30] & $37(29.8)$ & $20(57.1)$ & $8.8485^{* *}$ & 0.003 \\
\hline \multicolumn{5}{|l|}{ Type of service $[30]^{c}$} \\
\hline Social services & $24(19.5)$ & $16(45.7)$ & $9.8937^{* *}$ & 0.002 \\
\hline Health services & $12(10.4)$ & $8(22.9)$ & $4.2299^{*}$ & 0.040 \\
\hline Drug treatment service used [30] & $3(3.2)$ & $2(6.5)$ & 0.6654 & 0.415 \\
\hline Would use service for DU's, if available. & $98(79.0)$ & $27(77.1)$ & 0.2578 & 0.879 \\
\hline
\end{tabular}

${ }^{*} \mathrm{p}<0.05$, ${ }^{* *} \mathrm{p}<0.01,{ }^{* * *} \mathrm{p}<0.001$.

a missing values.

${ }^{b}$ of those who reported problems.

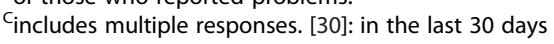

related harms among female crack users in Brazil constitutes an urgent intervention need.

Second, our data indicate higher prevalence, and more diversified patterns of (current) poly-drug use (including alcohol, marijuana, and cocaine) among male than among female crack users. These differences are notable, in particular since - with the exception of cocaine couse - they are mostly absent when 'lifetime' histories for these drugs (data not shown) are considered; moreover, almost 4 in 5 women (twice as many compared to men) reported a 'lifetime' history of inhalants/solvents. These gendered co-drug use patterns - and specifically the more pronounced current 'mono'-crack use profiles among females - point to a number of potential dynamics. The drug use pathways into crack use may differ between males and females; further, it is a worthwhile question whether the disappearance of inhalant/solvent use among females is mainly an ecologically driven or a 'drug use career' effect $[1,4]$. While tobacco and marijuana are used by most female crack users (and have been shown in other crack user populations to be used in combination with crack in order to modify effects) [61,62], women may either not desire, or may not have available or be able to afford the other drugs - alcohol and/or cocaine - which were commonly co-used by men. Additional inquiries - e.g., including qualitative/ ethnographic investigations - should investigate these 




Figure 1 Results of chi-squared automatic interaction detector (CHAID) model for study sample with 'sex' as dependent outcome variable.

differences, as these may entail implications for health consequences and intervention/treatment needs (e.g. in respect to poly-dependence, physical co-morbidities, etc.) [4,63,64].

A third key area of differences concerns health risk and status indicators. While men and women indicated overall similar physical health profiles, the differences in
BBV status - in particular HIV, with women reporting elevated levels - are noteworthy. Since drug injecting histories - the most common cause of HIV transmissions among illicit drug users - are close to absent in our study population, we must assume that most HIV infections were caused by sexual transmission pathways 
$[27,29,65]$. On this basis, our data suggest that the common involvement in sex work activities and associated sexual risk behaviors among females in our sample constituted a primary risk factor for increased BBV transmission and status levels [35,45,51,59,66,67]. Studies conducted elsewhere have found crack use to be an independent predictor of HIV and other BBV (e.g., HCV) transmissions among drug user populations [68-71]. Our data underscore the urgent need for targeted HIV and other BBV prevention and treatment measures in the study population, yet primarily among female crack users, with a primary emphasis on sexual risk reductions. Examples of peer- or community-based interventions - e.g., outreach programs and/or brief cognitive-behavioral interventions - aiming at sex-related risk behaviors among female crack users have been implemented elsewhere with positive results [72-75].

A further difference is related to the substantially lower levels of self-rated mental health among female participants. While these differences were not shown for mental health 'problems', and while the self-assessment of one's own mental health status constitutes a subjective exercise, somewhat higher levels of certain mental health problem symptoms and/or disorders among female drug - including stimulant - users have been documented elsewhere; in particular, depression, anxiety and PTSD symptom levels have been found to be higher among female users $[1,2,9,76]$. These mental health problems are commonly associated with stimulant misuse, and hence may burden female participants in our study population more distinctly than men and, consequently, lead to more intensive and/or problematic substance use behaviors [77-79]. While these data underscore the need for interventions and care focusing on cooccurring mental health problems among female crack users, such problems are common among male users as well and require general and integrated attention in targeted services for the study population.

Finally, we found substantively higher social and health service utilization rates - including higher HIV and HCV testing rates - among female crack users in our sample, [80]. While women in Brazil generally indicate higher health service attendance, multiple possible explanations and implications exist for these differences in our study population [81]. Overall, our data seem to suggest a somewhat - yet only partially closer - connection and involvement of female crack users with care services, which may suggest that women in our study's local contexts find these services more accessible or useful for their needs (even though most services were utilized by less than half of women, meaning that the majority of women did not access any of these services). Previous data has documented that - despite substantive recent investments in and expansions of psycho-social and other treatment services for psychoactive drug users in Brazil (e.g., CAPS-AD; [82]) - many crack users experience major barriers and problems with existent service offers, and only few utilize or access them [33,83,84]. The observed sex-based differences in service utilization may have other gender-specific reasons, e.g., higher use of universal pre-natal care related services - including sexual health and BBV testing - offered to women in Brazil $[51,85,86]$. While the present study did not collect relevant data to explain these dynamics in more detail, it is documented that many female crack users in Brazil have children, and thus pre-natal histories [35,37,43]. Female crack users may also be better connected to basic (e.g., outreach) care through local services or interventions specifically targeting sex workers $[50,87,88]$.

Potential implications arise from these differential service utilization profiles. Especially given the predominant general 'marginalization' of crack users, improved connections or involvement with social or health services would likely allow for improved delivery of or referrals to other - including general health, prevention or treatment - services; this is much more difficult with drug users who are completely disconnected from the service system $[57,89,90]$. It is further documented that BBV (e.g., $\mathrm{HIV}, \mathrm{HCV}$ ) testing is important for both creating awareness in regards to disease status and risk behavior changes, as well as for initiating effective treatment among risk populations [91-95]. Thus, the observed differential service utilization patterns between male and female crack users ought to be better understood towards improved intervention development and delivery.

Notably, the service utilization differences did not hold for treatment utilization specifically, where less than one in ten participants in both groups reported any recent involvement. This may imply various reasons, including lack of perceived need for treatment, limited availability or access barriers; recent data have suggested that all of these factors may be at work in the study population [33]. While other studies have emphasized distinct treatment and service needs for women drug users, it appears - despite recent expansions of addiction treatment services in Brazil - that major gaps in treatment offers, access and utilization for crack users in Brazil in general continue to exist which urgently ought to be addressed $[13,33,35,40,44,83]$. This observation is supported by the high proportion of (both male and female) users expressing desire to utilize improved service offers for drug users if these were available.

Our study has several potential limitations. It relied on a community-based convenience sample which may include selection biases and compromise generalizability of results; in addition, most data (except for biological tests) were based on self-report which are not objectively verifiable; however our study included key methodological provisions 
(e.g., subject anonymity, study procedures independent from service provision, etc.) for enhanced validity, and data from similar study designs have shown to be valid [96]. The sample, and key data values reported, were relatively small, potentially compromising analytical power. The study protocol did not include clinical or diagnostic assessments (e.g., for dependence) to formally assess care (e.g., treatment) needs. The gender sub-samples were comprised of participants from two different study locations, where ecological or contextual differences (e.g., drug availability or costs, use cultures, service offers, etc.) may have influenced individual behaviors or characteristics.

\section{Conclusions}

Our study documented several important differences in drug use, health and service indicators between young male and female crack users in Brazil. Given the prevalence of crack use in Brazil, these data illustrate the urgent need for gender-specific interventions in several (including targeted prevention, treatment) realms towards reducing the extensive related health and social problem burden of crack use.

\section{Abbreviations}

Anti-HAV: Hepatitis A virus antibody; Anti-HBc: Hepatitis B core antibody; Anti-HBs: Hepatitis B surface antibody; Anti-HCV: Hepatitis C virus antibody; BBV: Blood borne virus; CAPS-AD: Centro de Atencao Psicossocial Alcool e Drogas; CHAID: Chi-squared automatic interaction detector; FIOCRUZ: Fundação Oswaldo Cruz; HBAg: Hepatitis B antigen; HCV: Hepatitis C virus; HIV: Human immunodeficiency virus; PTSD: Post-traumatic stress disorder; SD: Standard deviation; SPSS: Statistical package for the social sciences; STD: Sexually transmitted disease.

\section{Competing interests}

The authors declare that they have no competing interests.

\section{Authors' contributions}

MC, TA, EL, FB, BF designed and co-led the study and the analysis plan. NB led the data analyses; NB and CB co-executed literature reviews. BF and NB led the write-up; all authors substantively contributed to data interpretation and manuscript draft revisions, and approved the draft as submitted.

\section{Authors' information}

$\mathrm{NB}, \mathrm{MSc}$, is a statistician and a PhD candidate in Epidemiology at the National Public Health School (ENSP), Rio de Janeiro, Brazil. She is currently a research associate at the Institute of Scientific and Technological Communication and Information in Health, Oswaldo Cruz Foundation (FIOCRUZ), Rio de Janeiro. Since 2010, she has worked as a teaching assistant at ENSP, for courses in Epidemiology and Statistics. Her research activities are concrentrated in the field of public health, with an emphasis on the epidemiology of HIV/AIDS and drug use/misuse, where she is using different statistical methodologies to better estimate hard-to-reach populations; she currently is the Co-Principal Investigator of a national multi-site survey of crack users in Brazil, funded by the National Secretariat on Drug Policy (SENAD). $\mathrm{CB}, \mathrm{BSC}$, is a research assistant at the Centre of Addiction and Mental Health in Toronto, Canada. She received her Honors Bachelor of Science at the University of Toronto, where she majored in human biology and social/cultural anthropology. $M C, M D, P h D$, is a practicing psychiatrist with over twenty years of experience in drug abuse treatment; he is also the Vice-President of the Brazilian Association of Multidisciplinary Studies on Drugs, and a coordinator for the Drug Abuse Research and Assistance Program (PROJAD), Institute of Psychiatry, Federal University of Rio de Janeiro, Brazil. He has been involved in several Brazilian multi-centered studies on substance use and mental health, and was the lead Investigator for a multi-city study of young crack users in Brazil. He is currently a consultant to the Brazilian Ministry of Health and to the Brazilian National Secretariat on Drug Policy. His research team has studied the neuropsychology of alcoholic fetal syndrome and crack use, and he has published works in the areas of drug abuse treatment, evaluation and drug policy.

$T A, M D, P h D$, is a professor in the Department of Family Health, and the Coordinator of the Harm Reduction Alliance program in the Faculty of Medicine at the Federal University of Bahia, Bahia State, Brazil. His research activities focus on prevention, treatment, education, and formulation of public policies related to psychoactive drug use. He is also the coordinator of the Center for Psychosocial Care for people who use alcohol and other drugs, and a member of the Academic Council for Research and Extension (CAPEX) at the Federal University of Bahia.

$F B, M D, P h D$, is a Senior Researcher, physician, and former Chair of Graduate Studies in Epidemiology and Biostatistics at the Oswaldo Cruz Foundation (FIOCRUZ), Rio de Janeiro, Brazil with extensive research experience in substance misuse and HIV, assessing community needs, and working with collaborators in Brazil and abroad. His research has explored the medical, social, and political dimensions of the AIDS epidemic in Brazil, as well as harms and risks associated with crack and cocaine. He has been the lead investigator on a number of large, multi-city studies investigating HIV, blood-borne infections and sexually transmitted diseases. His research team has developed new methods for assessing the health needs and vulnerabilities of impoverished and marginalized populations.

$E L, M D, P h D$, is a psychiatrist with over twenty years of experience in clinical treatment, and a coordinator of the Regional Center for Health Team Education on Alcohol and Drug Abuse in the Northern region of Rio de Janeiro State, Brazil. She teaches medical anthropology at the Medical School of the Federal University of Rio de Janeiro (UFRJ; Macaé campus), and is also a visiting professor in postgraduate studies at UNICAMP (State University of Campinas) Medical School. Her main research foci include outcomes of drug abuse treatment in public health facilities; the co-morbidity of drug abuse and mental health problems; and qualitative studies in public health. $\mathrm{BF}, \mathrm{PhD}$, is Professor and CIHR/PHAC Chair in Applied Public Health in the Faculty of Health Sciences, as well as Director of the Centre for Applied Research in Mental Health and Addictions (CARMHA) at Simon Fraser University, Vancouver, Canada; he is also a Senior Scientist in Social and Epidemiological Research, Centre for Addiction and Mental Health (CAMH), Toronto, and Professor (status) in the Department of Psychiatry, University of Toronto, Canada. His main research foci comprise the epidemiology and harms of and interventions for illicit and prescription drug misuse and key co-morbidities, including mental health and blood borne viruses; he has active research collaborations with academic partners in North and South America as well as Europe.

\section{Acknowledgments}

The underlying research for this study was supported by a grant from the Ministry of Health of Brazil (M.C., Lead Investigator), as well as received in-kind support from the Office of International Health, Centre for Addiction and Mental Health (CAMH). The present analysis was co-supported by research exchange funds from the Association of Universities and Colleges of Canada (AUCC). B.F. acknowledges funding support from a CIHR/PHAC Chair in Applied Public Health.

\section{Author details}

${ }^{1}$ Institute of Psychiatry, Federal University of Rio de Janeiro, Rio de Janeiro, Brazil. ${ }^{2}$ Department of Community and Family Health, Federal University of Bahia, Salvador, Brazil. ${ }^{3}$ Institute of Communication and Scientific Information \& Technology for Health, Oswaldo Cruz Foundation, Rio de Janeiro, Brazil. ${ }^{4}$ Centre for Applied Research in Mental Health and Addiction, Faculty of Health Sciences, Simon Fraser University, Vancouver, Canada. ${ }^{5}$ Social \& Epidemiological Research, Centre for Addiction and Mental Health, Toronto, Canada.

Received: 26 March 2014 Accepted: 25 July 2014

Published: 28 August 2014

\section{References}

1. Brady KT, Randall CL: Gender differences in substance use disorders. Psychiatr Clin North Am 1999, 22(2):241-252.

2. Pelissier B, Jones N: A Review of Gender Differences Among Substance Abusers. Crime Deling 2005, 51(3):343-372. 
3. Johnson PB, Richter L, Kleber HD, McLellan AT: Telescoping of Drinking-Related Behaviors: Gender, Racial/Ethnic, and Age Comparisons. Subst Use Misuse 2005, 40(8):1139-1151.

4. Hernandez-Avila CA, Rounsaville BJ, Kranzler HR: Opioid-, cannabis- and alcohol-dependent women show more rapid progression to substance abuse treatment. Drug Alcohol Depend 2004, 74(3):265-272.

5. Westermeyer J, Boedicker AE: Course, severity, and treatment of substance abuse among women versus men. Am J Drug Alcohol Abuse 2000, 26(4):523-535.

6. Fuchs CS, Stampfer MJ, Colditz GA, Giovannucci EL, Manson JE, Kawachi I, Hunter DJ, Hankinson SE, Hennekens CH, Rosner B: Alcohol Consumption and Mortality among Women. N England J Med 1995, 332(11):1245-1250.

7. Holdcraft LC, lacono WG: Cross-generational effects on gender differences in psychoactive drug abuse and dependence. Drug Alcohol Depend 2004, 74(2):147-158.

8. Cocozza JJ, Jackson EW, Hennigan K, Morrissey JP, Reed BG, Fallot R, Banks S: Outcomes for women with co-occurring disorders and trauma: Program-level effects. J Subst Abuse Treat 2005, 28(2):109-119.

9. Brooner R, King VL, Kidorf M, Schmidt CW, Bigelow GE: Psychiatric and substance use comorbidity among treatment-seeking opioid abusers. Arch Gen Psychiatry 1997, 54(1):71-80.

10. Kessler RC, Nelson CB, McGonagle KA, Edlund MJ, Frank RG, Leaf PJ: The epidemiology of co-occurring addictive and mental disorders: implications for prevention and service utilization. Am J Orthopsychiatry 1996, 66(1):17-31.

11. Morrissey JP, Ellis AR, Gatz M, Amaro H, Reed BG, Savage A, Finklstein N, Mazelis R, Brown V, Jackson EW, Banks S: Outcomes for women with co-occurring disorders and trauma: program and person-level effects. J Subst Abuse Treat 2005, 28(2):121-133.

12. Lynch WJ, Roth ME, Carroll ME: Biological basis of sex differences in drug abuse: preclinical and clinical studies. Psychopharmacology (Berl) 2002, 164(2):121-137.

13. Greenfield SF, Brooks AJ, Gordon SM, Green CA, Kropp F, McHugh RK, Lincoln M, Hien D, Miele GM: Substance abuse treatment entry, retention, and outcome in women: A review of the literature. Drug Alcohol Depend 2007, 86(1):1-21.

14. Hansen H, Alegria M, Caban CA, Pena M, Lai S, Shrout P: Drug Treatment, Health, and Social Service Utilization by Substance Abusing Women from a Community-Based Sample. Med Care 2004, 42(11):1117-1124.

15. Kerwin ME: Collaboration between Child Welfare and Substance-Abuse Fields: Combined Treatment Programs for Mothers. J Pediatr Psychol 2005, 30(7):581-597.

16. Simpson M, McNulty J: Different needs: women's drug use and treatment in the UK. Int J Drug Policy 2008, 19(2):169-175.

17. Wechsberg WM, Craddock SG, Hubbard RL: How are women who enter substance abuse treatment different than men?: A gender comparison from the drug abuse treatment outcome study (DATOS). Drugs Society 1998, 13(1-2):97-115.

18. Day $M$, Norman LR: An exploration of gender differences in the initiation of and attitudes toward crack cocaine use in the English-speaking Caribbean. Addict Res Theory 2007, 15(3):285-297.

19. Booth RE: Gender differences in high-risk sex behaviors among heterosexual drug injectors and crack smokers. Am J Drug Alcohol Abuse 1995, 21(4):419-432.

20. Pope SK, Falck RS, Carlson RG, Leukefeld C, Booth BM: Characteristics of rural crack and powder cocaine use: gender and other correlates. Am J Drug Alcohol Abuse 2011, 37(6):491-496.

21. Tolentino J, Lyons T, Goldstein PJ: Respiratory Illness, Gender, and Crack Cocaine Cessation Among Jail Detainees. J Correct Health Care 2007, 13(3):170-179

22. Tortu S, Goldstein M, Deren S, Beardsley M, Hamid R, Ziek K: Urban crack users: gender differences in drug use, HIV risk and health status. Women Health 1998, 27(1-2):177-189.

23. Tull MT, Gratz KL, Weiss NH: Exploring associations between borderline personality disorder, crack/cocaine dependence, gender, and risky sexual behavior among substance-dependent inpatients. Personal Disord 2011, 2(3):209-219

24. Lejuez CW, Bornovalova MA, Reynolds EK, Daughters SB, Curtin JJ: Risk Factors in the Relationship Between Gender and Crack/Cocaine. Exp Clin Psychopharmacol 2007, 15(2):165-175.

25. Henskens R, Mulder CL, Garretsen H, Bongers I, Sturmans F: Gender differences in problems and needs among chronic, high-risk crack abusers: Results of a randomized controlled trial. J Subst Use 2005 10(2-3):128-140.

26. Logan TK, Cole J, Leukefeld C: Gender differences in the context of sex exchange among individuals with a history of crack use. AIDS Educ Prev 2003, 15(5):448-464.

27. Booth RE, Kwiatkowski CF, Chitwood DD: Sex related HIV risk behaviors: differential risks among injection drug users, crack smokers, and injection drug users who smoke crack. Drug Alcohol Depend 2000, 58(3):219-226.

28. McCoy HV, Wasserman A: Gender differences in condom usage among rural crack-using men and women. Women Health 2001, 33(1-2):143-162

29. Strathdee SA, Sherman SG: The role of sexual transmission of HIV infection among injection and non-injection drug users. J Urban Health 2003, 80(4 Suppl 3):iii7-iii 14.

30. Shannon K, Rusch M, Morgan R, Oleson M, Kerr T, Tyndall MW: HIV and $\mathrm{HCV}$ prevalence and gender-specific risk profiles of crack cocaine smokers and dual users of injection drugs. Subst Use Misuse 2008, 43(3-4):521-534.

31. McCoy HV, Miles C: A gender comparison of health status among users of crack cocaine. J Psychoactive Drugs 1992, 24(4):389-397.

32. Henskens R, Garretsen H, Hongers I, Van Dijk A, Sturmans F: Effectiveness of an outreach treatment program for inner city crack abusers: Compliance, outcome, and client satisfaction. Subst Use and Misuse 2008, 43(10):1464-1475.

33. Cruz MS, Andrade T, Bastos Fl, Leal E, Bertoni N, Lipman L, Burnett C, Fischer B: Patterns, Determinants and Barriers of Health and Social Service Utilization among Young Urban Crack Users in Brazil. BMC Health Serv Res 2013, 13:536.

34. Bastos Fl: Against the tide: current perspectives in Brazilian drug policy. Cad Saude Publica 2013, 29(2):216-218.

35. Nappo SA, Sanchez Z, De Oliveira LG: Crack, AIDS, and women in São Paulo, Brazil. Subst Use Misuse 2011, 46(4):476-485.

36. Raupp L, Adorno RC: Crack usage circuits in the downtown area of the city of São Paulo. Cien Saude Colet 2011, 16(5):2613-2622.

37. Bastos Fl, Bertoni N: Pesquisa Nacional sobre o uso de crack: quem são os usuários de crack e/ou similares do Brasil? Quantos são nas capitais brasileiras? Rio de Janeiro: ICICT/FIOCRUZ; 2014.

38. Carlini AE, Galduroz JCF, Noto AR, Nappo SA: Il levantamento domiciliar sobre o uso de drogas psicotrópicas no Brasil: estudo envolvendo as 108 maiores cidades do país: 2005. São Paulo: CEBRID (Centro Brasileiro de Informações Sobre Drogas Psicotrópicas) and UNIFESP (Universidade Federal de São Paulo); 2006.

39. Cruz MS, Andrade T, Bastos Fl, Leal E, Bertoni N, Villar LM, Tiesmaki M, Fischer B: Key drug use, health and socio-economic characteristics of young crack users in two Brazilian cities. Int J Drug Policy 2013, 24(5):432-438.

40. Horta RL, Horta BL, Rosset AP, Horta CL: Crack cocaine users who attend outpatient services. Cad Saude Publica 2011, 27(11):2263-2270.

41. Pillon SC, Cardoso L, Pereira GAM, Mello E: Profile of the elderly assisted in a psychosocial care center: alcohol and other drugs. Esc Anna Nery 2010, 14(4):742-748.

42. Mombelli MA, Marcon SS, Costa JB: Characterization of psychiatric admissions for detoxification of drug addicted adolescents. Rev Bras Enferm 2010, 63(5):735-740.

43. Costa GM, Soibelman M, Zanchet DL, Costa PM, Salgado CAl: Pregnant crack addicts in a psychiatric unit. J Bras Psiquiatr 2012, 61(1):8-12.

44. Pedroso RS, Kessler F, Pechansky F: Treatment of female and male inpatient crack users: a qualitative study. Trends Psychiatry Psychother 2013, 35(1):36-45.

45. Carvalho HB, Seibel SD: Crack cocaine use and its relationship with violence and HIV. Clinics (Sao Paulo) 2009, 64(9):857-866.

46. Oliveira LG, Nappo SA: Crack-cocaine in Sao Paulo: accessibility, market strategies and ways of use. Rev Psiquiatr Clin 2008, 35(6):212-218.

47. Dunn J, Laranjeira RR: HIV-risk behaviour among non-heroin using cocaine injectors and non-injectors in São Paulo, Brazil. AIDS Care 2000, 12(4):471-481.

48. Ferri CP, Gossop M, Laranjeira RR: High dose cocaine use in São Paulo: a comparison of treatment and community samples. Subst Use Misuse 2001, 36(3):237-255

49. Jorge MS, Quindere PH, Yasui S, Albuguerque RA: The ritual of crack consumption: socio-anthropological aspects and impacts on the health of users. Cien Saude Colet 2013, 18(10):2909-2918. 
50. Nunes CL, Andrade T, Galcao-Castro B, Bastos Fl, Reingold A: Assessing risk behaviors and prevalence of sexually transmitted and blood-borne infections among female crack cocaine users in Salvador-Bahia, Brazil. Braz J Infect Dis 2007, 11(6):561-566.

51. Malta M, Monteiro S, Lima RM, Bauken S, Marco A, Zuim GC, Bastos Fl, Singer M, Strathdee SA: HIV/AIDS risk among female sex workers who use crack in Southern Brazil. Rev Saude Publica 2008, 42(5):830-837.

52. Moreira MM, Barbosa GL, Laranjeira R, Mitsuhiro SS: Alcohol and crack/ cocaine use in women: a 14-year cross-sectional study. J Addict Dis 2014 doi:10.1080/10550887.2014.882726.

53. Breiman L, Friedman J, Stone CJ, Olshen R: Classification and regression trees. Pacific Grove: Wadsworth International Group; 1984.

54. Magidson J, Vermunt JK: An Extension of the CHAID Tree-based Segmentation Algorithm to Multiple Dependent Variables. In Classification - the Ubiquitous Challenge. Edited by Weihs C, Gaul W. Berlin: Springer; 2005:176-183.

55. Surratt HL, Inciardi JA, Kurtz SP, Kiley MC: Sex work and drug use in a subculture of violence. Crime Deling 2004, 50(1):43-59.

56. Miller $M$, Neaigus A: Networks, resources and risk among women who use drugs. Soc Sci Med 2001, 52(6):967-978

57. Fischer B, Coghlan M: Crack in North American cities: the neglected 'epidemic'. Addiction 2007, 102(9):1340-1341.

58. Erickson PG, Butters J, McGillicuddy P, Hallgren A: Crack and prostitution: gender, myths, and experiences. J Drug Issues 2000, 30(4):767-788.

59. Inciardi JA, Surratt HL: Drug use, street crime, and sex-trading among cocaine-dependent women: Implications for public health and criminal justice policy. J Psychoactive Drugs 2001, 33(4):379-389.

60. Shannon K, Rusch M, Shoveller J, Alexson D, Gibson K, Tyndall MW: Mapping violence and policing as an environmental-structural barrier to health service and syringe availability among substance-using women in street-level sex work. Int J Drug Policy 2008, 19(2):140-147.

61. Labigalini E, Rodrigues $L R$, Da Silveira DX: Therapeutic use of cannabis by crack addicts in Brazil. J Psychoactive Drugs 1999, 31(4):451-455.

62. Andrade T, Santiago L, Amari E, Fischer B: 'What a pity!' - Exploring the use of 'pitilho' as harm reduction among crack users in Salvador, Brazil. Drugs Edu Prev Policy 2011, 18(5):382-386.

63. Nelson-Zlupko L, Kauffman E, Dore MM: Gender differences in drug addiction and treatment: implications for social work intervention with substance-abusing women. Soc Work 1995, 40(1):45-54.

64. Ashley OS, Marsden ME, Brady TM: Effectiveness Of Substance Abuse Treatment Programming For Women: A Review. Am J Drug Alcohol Abuse 2003, 29(1):19-53.

65. Strathdee S, Galai N, Sefaiean M, Celentano DD, Vlahov D, Johnson L, Nelson KE: Sex differences in risk factors for HIV seroconversion among injection drug users: A 10-year perspective. Arch Intern Med 2001, 161(10):1281-1288.

66. Hoffman JA, Klein H, Eber M, Crosby H: Frequency and intensity of crack use as predictors of women's involvement in HIV-related sexual risk behaviors. Drug Alcohol Depend 2000, 58(3):227-236.

67. Logan TK, Leukefeld C: Sexual and drug use behaviors among female crack users: a multi-site sample. Drug Alcohol Depend 2000, 58(3):237-245.

68. Scheinmann $\mathrm{R}$, Hagan $\mathrm{H}$, Lelutiu-Weinberger C, Stern R, Des Jarlais DC, Flom PL, Strauss S: Non-injection drug use and Hepatitis C Virus: A systematic review. Drug Alcohol Depend 2007, 89(1):1-12.

69. Haydon E, Fischer B: Crack use as a public health problem in Canada - call for an evaluation of 'safer crack use kits'. Can J Public Health 2005, 96(3):185-188.

70. Nyamathi AM, Dixon EL, Gelberg L: Risk factors for hepatitis C virus infection among homeless adults. J Gen Int Med 2002, 17(2):134-143.

71. DeBeck K, Kerr T, Li K, Fischer B, Buxton J, Montaner J, Wood E: Smoking of crack cocaine as a risk factor for HIV infection among people who use injection drugs. CMAJ 2009, 181(9):585-589.

72. Semaan $S$, Des Jarlais DC, Sogolow E, Johnson WD, Hedges LV, Ramirez G, Flores SA, Normal L, Sweat MD, Needle R: A meta-analysis of the effect of HIV prevention interventions on the sex behaviors of drug users in the United States. J Acquir Immune Defic Syndr 2002, 30(Suppl 1):S73-S93.

73. Kral AH, Bluthenthal RN, Lorvick J, Gee L, Bacchetti P, Edlin BR: Sexual transmission of HIV-1 among injection drug users in San Francisco, USA: risk-factor analysis. Lancet 2001, 357(9266):1397-1401.

74. Sterk CE, Theall KP, Elifson KW: Effectiveness of a risk reduction intervention among African American women who use crack cocaine. AIDS Educ Prev 2003, 15(1):15-32.
75. Wechsberg WM, Luseno WK, Lam WK, Parry CD, Morojele NK: Substance use, sexual risk, and violence: HIV prevention intervention with sex workers in Pretoria. AIDS Behav 2006, 10(2):131-137.

76. Chander G, McCaul ME: Co-occurring psychiatric disorders in women with addictions. Obstet Gynecol Clinof North Am 2003, 30(3):469-481.

77. Falck RS, Wang J, Siegal HA, Carlson RG: The prevalence of psychiatric disorder among a community sample of crack cocaine users: an exploratory study with practical implications. J Nerv Ment Dis 2004, 192(7):503-507.

78. Khantzian RJ: The self-medication hypothesis of substance use disorders: a reconsideration and recent applications. Harv Rev Psychiatry 1997, 4(5):231-244.

79. Compton WM, Cottler LB, Jacobs JL, Ben-Abdallah A, Spitznagel EL: The role of psychiatric disorders in predicting drug dependence treatment outcomes. Am J Psychiatry 2003, 160(5):890-895.

80. Gomes R, Nascimento EF, Araujo FC: Why do men use health services less than women? Explanations by men with low versus higher education. Cad Saude Publica 2007, 23(3):565-574.

81. Bertakis KD, Azari R, Helms LJ, Callahan EJ, Robbins JA: Gender differences in the utilization of health care services. J Fam Pract 2000, 49(2):147-152.

82. Nascimento-Alves DS, da Silva PRF, Costa NR: Advances and challenges of psychiatric reform in Brazil 22 years after the Caracas declaration. Medwave 2012, 12(10):e5545.

83. Malta M, Cavalcanti S, Gliksman L, Adlaf E, Hacker A, Bertoni N, Massard E, Bastos Fl: Behavior and major barriers faced by non-injectable drug users with HBV/HCV seeking treatment for hepatitis and drug addiction in Rio de Janeiro. Brazil Ciên Saúde Colet 2011, 16(12):4777-4786.

84. Andreoli SB, Almeida-Filho N, Martin D, Mateus MD, Mari J: Is psychiatric reform a strategy for reducing the mental health budget? The case of Brazil. Rev Bras Psiquiatr 2007, 29(1):43-46.

85. Szwarcwald CL, Barbosa A, Souza-Junior PR, Lemos KR, Frias PG, Luhm KR, Holcman MM, Esteves MA: HIV testing during pregnancy: use of secondary data to estimate 2006 test coverage and prevalence in Brazil. Braz J Infect Dis 2008, 12(3):167-172.

86. Guilhem D, Azevedo AF: Brazilian public policies for reproductive health: family planning, abortion and prenatal care. Dev World Bioeth 2007, 7(2):68-77.

87. Rodriguez CM, Marques LF, Touze G: HIV and injection drug use in Latin America. AIDS 2002, 16(Suppl 3):S34-S41.

88. Inciardi JA, Surratt HL, Kurtz SP: HIV, HBV, and HCV infections among drug-involved, inner-city, street sex workers in Miami. Florida AIDS Behav 2006, 10(2):139-147.

89. Shannon K, Strathdee SA, Shoveller J, Rusch M, Kerr T, Tyndall MW: Structural and Environmental Barriers to Condom Use Negotiation With Clients Among Female Sex Workers: Implications for HIV-Prevention Strategies and Policy. Am J Public Health 2009, 99(4):659-665.

90. Kurtz SP, Surratt HL, Kiley MC, Inciardi JA: Barriers to health and social services for street-based sex workers. J Health Care Poor Underserved 2005, 16(2):345-361.

91. Marks G, Gardner LI, Craw J, Crepaz N: Entry and retention in medical care among HIV-diagnosed persons: a meta-analysis. AIDS 2010, 24(17):2665-2678.

92. Rhodes T, Singer M, Bourgois P, Friedman SR, Strathdee SA: The social structural production of HIV risk among injecting drug users. Soc Sci Med 2005, 61(5):1026-1044.

93. Hagan H, Campbell J, Thiede H, Strathdee S, Ouellet L, Kapadia F, Hudson S, Garfein RS: Self-Reported Hepatitis C Virus Antibody Status and Risk Behavior in Young Injectors. Public Health Rep 2006, 121(6):710-719.

94. Wood E, Kerr T, Tyndall MW, Montaner JS: A review of barriers and facilitators of HIV treatment among injection drug users. AIDS 2008, 22(11):1247-1256.

95. Swan D, Long J, Carr O, Flanagan J, Irish H, Keating S, Keaveney M, Lambert J, McCormick PA, McKiernan S, Moloney J, Perry N, Cullen W: Barriers to and Facilitators of Hepatitis C Testing, Management, and Treatment Among Current and Former Injecting Drug Users: A Qualitative Exploration. AIDS Patient Care STDS 2010, 24(12):753-762.

96. Darke S: Self-report among injecting drug users: A review. Drug Alcohol Depend 1998, 51(3):253-263.

doi:10.1186/s12939-014-0070-x

Cite this article as: Bertoni et al:: Exploring sex differences in drug use, health and service use characteristics among young urban crack users in Brazil. International Journal for Equity in Health 2014 13:70. 